\title{
O PARTIDO REPUBLICANO FEDERAL E O PROCESSO POLÍTICO-PARTIDÁRIO BRASILEIRO.
}

\author{
$\overline{-10}$ \\ J. S. WITTER \\ Disciplina: História do Brasil.
}

O objetivo deste artigo é analisar a participação do PRF na vida política do início de nosso período republicano e ao mesmo tempo tentar explicitar e entender como se deu, a partir do Governo de Floriano, a atuação dos civis, no processo político-partidário nos primeiros anos de nosso regime republicano.

Cremos necessária uma tentativa de caracterização do período que tentamos estudar e ao mesmo tempo uma visão do processo político-partidário brasileiro desde o final do Império e até o momento em foco.

"A prática política do Império, ao mesmo tempo em que desprestigiara os partidos em sentido nacional, consolidara os agrupamentos provinciais em função dos mecanismos eleitorais em vigor. Costuma-se diferenciar o Partido Liberal como originário dos g upos liberais articulados depois da Abdicação, propugnadores do Ato Adicional e de um modo geral representantes dos interesses da burguesia urbana, do capitalismo comercial e das conviç̧ões dos intelectuais progressistas, escritores, jornalistas, professores, magistrados; o Partido Conservador teria se originado a partir de uma junção de Liberais da direita e antigos restauradores de esquerda, representando os interesses econômicos ligados à lavoura. Indícios de que no fundo representavam pouca diferença entre si são suas cisões e recomposições: a Liga Progressista (conservadores moderados e Liberais), "os históricos" (os liberais contrários à Liga Progressista, pelo fato de representar união com elementos conservadores defensores intransigentes da ordem), - Centro Liberal (ala dos liberais históricos que procurou reno- 
var o Partido Liberal), o Partido Radical( liberais extremados que acabaram evo'uindo para o Partido Republicano)" (1).

Com a República, com o situacionismo favoravel a Deodoro, tanto liberais quanto conservadores, passaram a aderir às hostes republicanas. O fenômeno do adesismo político, característica de todas as épocas de nossa vida política, tão pouco estudado, tem uma página antologica na Gazeta de Notícias do Rio de Janeiro:

"Cidadãos - O cidadão chronista participa-vos que tambem adhere. Saude e fraternidade.

Pois que foi esta a nota dominante da semana - as adhesões - convém deixar desde já expressa que a Chronica, não tendo razões especiaes para pensar de diverso modo, procura o seu minúsculo logar no vasto adhesivo em que há pouco transformouse este paiz, e vem, sem philarmonica nem discurso engatilhado, dizer aos cidadãos governantes; e aos cidadãos governados que a sua adherencia é completa.

A bem dizer, e com franqueza, não adherir seria neste momento a posição mais interessante para aquelle que amasse a notoriedade; tão ce.to é que do Amazonas ao Prata, salva a excepção impar da Tribuna Liberal, toda a população brasileira descobriu no dia 16 do andante que era republicana até os ossos, republicana de quatro costados, republicana de família, como vício ou como herança que fosse.

Mas a notoriedade é um perigo, e que o diga o próprio Governo $\mathbf{P}$ :ovisório que mais trabalho tem tido em aturar os adherentes, do que os passados governos monarchicos em colocar os seus parentes.

Uma chusma, cidadãos; uma chusma de convencidos, de discursadores e declarantes, que, grupo por grupo, ou um a um, tem vindo ao quartel-general fazer as suas declarações e protestos, sem se recordar que de mais impo:tantes assumptos cura neste momento o governo, que sobre seus hombros tomou tão grave responsabilidade!

Menos adherentes, um grupo de resistência - e o Governo Provisório teria talvez maior satisfação ao completar a obra estupenda realizada com tal felicidade, com tão assombroso resultado.

(1). - Cf. Rosa Maria Godoy Silveira, O Federalismo na Politica dos Governadores (Relacionamento político-administrativo entre União e Estados). Tese de Mestrado no Departamento de História da Faculdade de Filosofia, Letras e Ciências Humanas da Universidade de São Paulo. 
Ao general Deodoro, por exemplo, deve ter custado um pouco aturar tantos adherentes. Deixando o leito, onde estava enfermo, e sahindo para a rua a dar batalha ao derradeiro ministério da monarchia, tudo podia esperar o bravo marechal, menos o que the sucedeu: suppunha ter de lutar, de ouvir passarem junto a si as balas, e afinal de contas, em vez de metralha retorica, em vez de cheiro de polvora - a massada dos discursos!

Não só dos representantes do sexo barbado, mas até do bello sexo; das senhoras, que até agora de assumptos tão alheios à política cuidavam, tem o Governo Provisório recebido adhesões! Adherem em grupo, e assim, evidenciada a tendencia adhesiva da quadra anormal que atravessamos, - lastimamos o pobre do Souvenir, que d'ora avante não mais fará a chronica elegante das fanfreluches... mas das adherencias e concomitantes opiniões políticas do sexo fraco!

Crianças das escolas, meninas que na vespera apenas se entretinham em fazer vestuarios para suas bonecas, arregimentamse e vão ao quartel-general dizer ao governo... que tambem adherem.

A classe medica, que ainda não encontrou ensejo de congregar-se para constituir uma associação beneficiente, desta vez encontrou ensejo opportuno para reunir-se, e, formada em batalhão patriotico, armado de bistoris e de esmagadores de Chassaignac, marcha para o Campo da Acclamação e vai até o Governo Provisório, dizer, como as crianças acima referidas... que tambem adhere! (...) (2).

No entanto, as agremiações republicanas que precederam à proclamação foram as bases para a política governamental dos primeiros anos da República e muitas já estavam consolidadas. Mas, onde não existiam foram criadas (3). Os exemplos de todo o país são muito significativos. Em Goiás, tão logo proclamada a República, instalou-se um governo de republicanos "em nome do povo" (4). Não foi, no entanto, uma organização tranquila para este grupo, pois a contestação não se fez esperar, em nome da necessidade de uma ruptura efetiva com os grupos dominantes, alegando os opositores que a "no-

(2). - A Proclamação da República e sua Repercussão. "Chronica da Semana", Gazeta de Notícias, in M.E. de Campos Porto, Apontamentos para a História da República dos Estados Unidos do Brazil. Rio de Janeiro, Imprensa Nacional, 1890, pp. 170-171.

(3). - Cf. Rosa Maria Godoy Silveira, opus. cit., p. 96.

(4). - Cf. Maria Augusta Sant'Anna Moraes, História de uma Oligarquia: os Bulhões. Goiânia, Oriente, 1974, p. 118. 
va" Junta Governativa era o continuismo dos Bulhões no poder. O lider Leopoldo de Bulhões era liberal. A solução foi mais uma "aderência" e os Bulhões se declararam "republicanos" (5).

Outro exemplo que merece ser lembrado é o do Rio Grande do Norte, onde Pedro Velho chamou para compor o governo antigos liberais e ex-conservadores (6). Ainda poderíamos lembrar o caso do Sertão dos Inhamuns (7). E poderíamos até mesmo basear-nos em inúmeras cidades do interior e do litoral paulistanos (8).

$\mathrm{O}$ adesismo, os arranjos imediatistas, os acordos locais parecem vir comprovar a tese de Afonso Arinos de Melo Franco quando, afirma ser

“a mentalidade republicana federal em primeiro lugar; em segundo anti-partidária, no sentido nacional" (9).

Essa mentalidade anti-partidária a que se refere Afonso Arinos e com a qual concordamos em parte merece uma certa análise, uma vez que, ao adotar esta posição, estamos, de certa forma, contrariando pontos de vista emitidos anteriormente, resultantes de nossas pesquisas vinculadas aos partidos políticos brasileiros. De fato, a tendência dos nossos políticos foi sempre a de não consolidar as tentativas feitas de se criar um Partido Nacional. Não obstante, algumas dessas tentativas tiveram grande significado na vida brasileira. Quando falamos em tentativas que tiveram real significado pensamos principalmente no PRF e no PRC, o primeiro vinculado ao grupo paulista e liderado por Glicério e o segundo ligado ao grupo do Rio Grande do Sul e liderado por Pinheiro Machado, estudado exaustivamente por Joseph Love. Tanto o PRF quanto o PRC se constituiram em modelos de agremiações partidárias que se multiplicariam durante a Primeira República, sempre pensadas por seus idealizadores em serem um Partido Nacional, mas sempre sobrevivendo nas suas manifestações regionais e locais.

(5). - Idem, ibidem.

(6). - CASCUDO (Luís da Câmara), História da República no Rio Grande do Norte; da Propaganda à Primeira Eleiçấo Direta para Governador. Rio de Janeiro, Edições do Val. 1965, p. 127 e segs.; SILVEIRA (Rosa Maria Godoy), opus. cit., p. 98; SILVA (Janice Teodoro da), Politica e Ideologia na Primeira República (O Exemplo do Rio Grande do Norte (1898-1930). Das oposições significativas às oposições neutralizadoras). Tese de Mestrado no Departamento de História da Faculdade de Filosofia, Letras e Ciências Humanas da Universidade de São Paulo. São Paulo, 1975.

(7). - CHANDLER (Billy Jaynes), The Feitosas and the Sertão dos Inhamuns; The History of a Family and a Community in Northeast Brazil, 1700-1930. Gainesville, University of Florida Press 1972, p. 103.

(8). - Cf. Rosa Maria Godoy Silveira, opus. cit., p. 100.

(9). - FRANCO (Afonso Arinos de Melo), História e Teoria dos Partidos Politicos no Brasil. São Paulo, Editora Alfa-Omega, 1974. 
Os políticos mais notórios sempre se mostraram pouco afeitos à disciplina partidária e à execução dos programas políticos estabelecidos nas convenções e reuniões partidárias. Exemplo típico é o de Campos Salles, republicano histórico, fundador do PRF juntamente com Glicério; durante as crises por que passou a agremiação, diria a respeito:

\begin{abstract}
"Sem rumo certo, de tendências indefinidas, não revestia nenhuma das condições essenciais dos altos fins a que se destina um partido bem constituido... O que havia na alta direção era, no fundo, um grupo de caudilhos políticos, todos igualmente soberanos e cioso cada um de sua influência pessoal... Foi dos escombros desta aberração política que sairam os agrupamentos em que se achou dividido o Congresso Nacional quando recebi a investidura do poder" (10).
\end{abstract}

Esta colocação de Campos Salles mostra o grau de indisciplina partidária, pois ele fora um dos homens do PRF e um dos batalhadores pela eleição de Prudente de Moraes em 1893. Quando da crise que levaria o Partido Republicano Federal à cisão, passaria ele à crítica violenta e à proposição de uma nova política, não mais apoiada num só partido político nacional, mas baseada no poder do Governador, a "Política dos Governadores" ou Política dos Estados, como preferia chama-la seu autor. A partir de então, o quadro político durante toda a República Velha se caracterizaria pelo desenvolvimento da mentalidade antipartidária a nivel nacional a que já nos referimos e ainda mais pela tentativa constante de fortificação do federalismo. Este evidentemente influiu de forma decisiva na formação de entidades políticas que acabam por ser sempre mais estaduais do que nacionais.

Mas, "catedral aberta a todos os credos" ou "mais uma frente comum do que um agrupamento político-ideológico", o certo é que o PRF se constituiu no modelo de todas as agremiações partidárias brasileiras, mormente durante os 40 anos da nossa experiência republicana. Todos os "partidos" políticos organizados a partir de 1893 tiveram sempre a caracteriza-los a falta de uma orientação ideológica, a falta de um conteudo programático preciso e objetivamente delineado, a falta de uma atuação efetiva em âmbito nacional. Dir-se-á que isto se explica pelo óbvio, ou seja, o óbvio da nossa tendência regionalista e descentralizadora calcada na política "coronelista" remanescente até mesmo do modelo imperial.

(10). - Cf. Manuel Ferraz de Campos Salles, Da Propaganda à Presidência. São Paulo, 1908, p. 227 e segs. 
Entretanto, parece-nos que esse óbvio da realidade regional não chega a ser um argumento plenamente satisfatório para se compreender um determinado momento da vida político-partidária republicana, o de transição e ajustamento dos organismos partidários brasileiros frente ao novo carater do Estado, de cunho federal. E, então, baseado na insuficiência do argumento que consideramos necessário uma análise sobre o papel do PRF. Pode-se dizer que essa análise equivale a colocar-nos na ótica federal para completar o que a realidade regional exprime - a ótica federada. Ainda, falar simplesmente no poder regional não explica a organicidade interna da agremiação.

Fernando Henrique Cardoso (11) traçou de forma precisa o quadro político do governo de Floriano Peixoto, no qual surgiu o PRF. A divisão das Forças Armadas, a multiplicação das dissidências, o não cumprimento efetivo da Constituição de 91 criavam conflitos que era preciso canalizar. Esta tarefa o presidente da República exerceu mediante aliança com um certo setor do Exército e com os republicanos paulistas e mediante a ênfase numa certa mística de ordem republicana a qual, para ser realmente conseguida, exigiu uma dupla articulação: de um lado, o emprego da força pelo próprio Floriano ia de encontro àquela ala radical dos meios militares e de outro, a garantia da ordem constitucional limitava a ação do jacobinismo. Para esta última tarefa, confiada basicamente aos republicanos paulistas, é que surgiu o PRF, como peça de estrutura do poder, vista por Floriano, no entanto, como um instrumento de controle da Câmara no conflito entre Executivo e Legislativo, um dos característicos desta fase de instabilidade inicial do regime republicano. Daí, pois que a agremiação tinha uma dupla finalidade: ao tentar congregar os políticos em âmbito nacional: se o seu moto principal era o de eleger o primeiro presidente civil, todavia era tambem um instrumento para tentar fortalecer o republicanismo ameaçado por esse clima de instabilidade.

Assim compreendida a função do partido, e se são óbvios os determinantes externos a ele que comprometeram sua existência em âmbito nacional, repetimos que há determinantes internos que tambem dificultaram o carater mais amplo do PRF. Mais especificamente e preocupados com isso é que tentamos tecer algumas reflexões em torno da composição da referida agremiação.

Considerado como uma "catedral que acolhia todos os credos" (12), o Partido Republicano Federal recebeu, incontestavelmente, as

(11). - Cf. o seu artigo "Dos Governos Militares a Prudente - Campos Sales" in História Geral da Civilização Brasileira. Tomo III, 19 volume. São Paulo: DIFEL, 1975, p. 43 e segs.

(12). - Cf. Sertório de Castro, A República que a Revolução Destruia. Rio de Janeiro. 1932, p. 119. 
mais diversas tendências e interesses políticos das diferentes áreas do país.

Tomando por base os homens que ocuparam as posições de mando podemos perfeitamente averiguar quão diferentes e até mesmo antagônicas eram as idéias defendidas por eles. Que dizer, então, daquele número enorme de integrantes do partido que nem siquer figurou em seus documentos mais importantes? Se daqueles podemos, embora com falhas, salientar os pontos de vista e até entende-los dentro e fora do partido, destes quase nada sabemos objetivamente.

A partir daquilo que de concreto ficou dos documentos da agremiação, constatamos que para. a sua formação contribuiram políticos de quase todos os Estados da Federação (13).

A tabela I, por exemplo, cuida da origem dos integrantes da agremiação partidária, tomando por base o local de nascimento de seus membros. Neste caso, conforme podemos constatar, todos os Estados da Federação estão representados, entre os cento e quatro signatários da ata de fundação do Partido. Excluidos os dados referentes aqueles partidários sobre os quais nada encontramos (14) e àqueles dos quais não deciframos a assinatura (15), alem dos portugueses naturalizados (16), podemos observar como estavam representadas as bases políticas do país, na nova agremiação que se organizara, em 1893.

Constatamos que em primeiro lugar, está Minas Gerais (11,53\%) e depois São Paulo, Pará e Rio de Janeiro $(8,64 \%)$ e em seguida a Bahia $(7,88 \%)$. Se a posição de Minas Gerais, ocupando o primeiro lugar, não nos surpreendeu, nem a de São Paulo e a do Rio de Janeiro, a colocação do Pará, no entanto, nos parece bastante peculiar. Está esse Estado equiparado a São Paulo e Rio de Janeiro em número de representantes que lá nasceram, e bem próximo de São Paulo e muito acima do Rio de Janeiro quanto aos homens enviados para as reuniões, conforme nos demonstra a Tabela II.

Acreditamos que a situação de destaque ocupada pelo Pará se prenda, entre outros fatores, à liderança indiscutivel de Lauro Sodré, que durante os primórdios da República fora o lider inconteste do PRP naquela região.

(13). - O único Estado não representado na Sessão de Instalação do Partido foi o Rio Grande do Sul. Cf. Tabela II.

(14). - Qualificados como "desconhecidos" ou "sem informações", em número de dois $(1,92 \%)$. $(8,64 \%)$.

(15). - Assinalados no item "Assinaturas llegiveis", em núme:o de nove

(16). - Eram dois os portugueses naturalizados $(1,92 \%)$. 
Tabela I. - Estados de origem, por nascimento, c'os signatários da Ata de Fundação do Partido.

ESTADO

Alagoas

Amazonas

Bahia

Ceará

Espírito Santo

Goiás

Mato Grosso

Maranhão

Minas Gerais

Pará

Paraná

Paraiba

Pernambuco

Piauí

Rio Grande do No:te

Rio Grande do Sul

Rio de Janeiro

Santa Catarina

São Paulo

Sergipe

Desconhecidos, sem informações

Portugal

Assinatura Ilegivel

Total

FREQUENCIA

2

2

8

4

2

5

2

5

12

9

1

1

7

3

2

1

9

4

9

3

2

2

9

104

*

\section{PORCENTAGEM}

$1,92 \%$

$1,92 \%$

$7,88 \%$

$3,84 \%$

$1,92 \%$

$4,80 \%$

$1,92 \%$

$4,80 \%$

$11,53 \%$

$8,64 \%$

$0,96 \%$

$0,96 \%$

$6,74 \%$

$2,88 \%$

$1,92 \%$

$0,96 \%$

$8,64 \%$

$3,84 \%$

$8,64 \%$

$2,88 \%$

$1,92 \%$

$1,92 \%$

$8,64 \%$

$100 \%$

Tabela II. - Representação por Estado dos signatários da Ata de Fundação do Partido.

ESTADO

Alagoas

Amazonas

Bahia

Ceará

Espírito Santo

Goiás

Mato Grosso

Maranhão

Minas Gerais

\section{FREQUENCIA}

1

4

6

6

4

6

1

4

11
PORCENTAGEM

$0,96 \%$

$3,84 \%$

$5,76 \%$

$5,76 \%$

$3,84 \%$

$5,76 \%$

$0,96 \%$

$3,84 \%$

$10,57 \%$ 


$\begin{array}{lrr}\text { Pará } & 9 & 8,64 \% \\ \text { Paraná } & 1 & 0,96 \% \\ \text { Paraiba } & 1 & 0,96 \% \\ \text { Pernambuco } & 6 & 5,76 \% \\ \text { Piauí } & 4 & 3,84 \% \\ \text { Rio Grande do Norte } & 2 & 1,92 \% \\ \text { Rio Grande do Sul } & & - \\ \text { Rio de Janeiro } & 4 & 3,84 \% \\ \text { Santa Catarina } & 5 & 4,80 \% \\ \text { São Paulo } & 10 & 9,61 \% \\ \text { Sergipe } & 3 & 2,88 \% \\ \text { Desconhecidos, sem } & & \\ \quad \text { informações } & 2 & 1,92 \% \\ \text { Distrito Federal } & 5 & 4,80 \% \\ \text { Assinatura Ilegivel } & 9 & 8,64 \% \\ \text { Total } & 104 & 100 \%\end{array}$

Poder-se-ia inquirir sobre a importância da apresentação desses dados. Qual a relevância que eles apresentam para o entendimento da organização partidária e mesmo para a compreensão da vida política nacional?

Cremos que se justifica plenamente a preocupação que tivemos com a determinação dos Estados de origem dos políticos que organizaram a agremiação da qual nos ocupamos, dadas as peculiaridades brasileiras no tocante às bases nas quais se assentam as lideranças partidárias. Aceita a tese da indiscutivel influência das famílias tradicionais sobre a atuação dos nossos políticos consequentemente podemos aceitar e entender os seus reflexos na vida das agremiações a que pertencem (17) .

Dadas as circunstâncias que precederam a organização do partido e depois de esboçado, a tentativa de seus líderes em transforma-lo numa agremiação efetivamente nacional explica a participação de quase todos os Estados nas reuniões para a elaboração dos estatutos e do programa partidário.

A Tabela II nos mostra a representação dos Estados na formação do PRF em termos de frequência e porcentagem. Neste caso, não se trata de mais uma busca do elemento nascido nesta ou naquela unidade da Federação. Tentamos constatar a representatividade dos Estados no seio do partido, o que não quer dizer que obrigatoriamente os ho-

(17) - Cf. Cid. Rabelo Horta, As famílias governamentais mineiras, in Segundo Seminário de Estudos Mineiros. Belo Horizonte. 1956, p. 44-91. 
mens enviados para representar Pernambuco, Santa Catarina ou qualquer outro Estado fosem nascidos nessas unidades da Federação.

Se compararmos, no entanto, a Tabela I com a Tabela II, iremos encontrar uma equivalência entre elas. Isto é, se na Tabela I existem mais elementos oriundos de Minas Gerais do que de São Paulo, e estes em maior número que os de Sergipe, assim por diante, tambem na Tabela II isso se dá, variando pura e tão somente a frequência com que se apresentam.

Uma outra tabela que procuramos organizar, nos demonstra o tipo de formação acadêmica dos componentes do PRF.

Tabela III. - Formação Acadêmica dos Signatários da Ata de Fundação do Partido.

$\begin{array}{lcc}\text { NATUREZA DO CURSO } & \text { FREQUENCIA } & \text { PORCENTAGEM } \\ \text { Belas Artes } & 1 & 0,96 \% \\ \text { Direito } & 48 & 46,15 \% \\ \text { Engenharia } & 7 & 6,74 \% \\ \text { Escola Militar } & 5 & 4,80 \% \\ \text { Letras e Filosofia } & 1 & 0,96 \% \\ \text { Medicina } & 18 & 17,30 \% \\ \text { Seminário } & 1 & 0,96 \% \\ \text { Desconhecidos, sem } & & \\ \quad \text { informações } & 7 & 6,74 \% \\ \text { Nenhum } & 7 & 6,74 \% \\ \text { Assinatura Ilegivel } & 9 & 8,64 \% \\ \text { Total } & 104 & 100 \%\end{array}$

Essa tabela está igualmente expressa em termos de frequência e porcentagem. Por ela observamos que o curso mais representado é o de Direito, abrangendo quase $50 \%$ do número de integrantes do PRF, mais precisamente $46,15 \%$. Em seguida, temos bem representada a Medicina, que apresenta um potencial de 17,3\%, seguida da Engenharia com $6,74 \%$. Excluidos os três últimos itens da Tabela III (18), notamos uma grande queda no percentual apresentado quando se trata de áreas tais como o clero, as artes, a filosofia e letras $(0,96 \%)$.

(*). - A porcentagem foi calculada sobre o total de assinaturas (104) e não sobre o total de cursos realizados, pois muitos' dos signatários fizeram mais de um curso.

(18). - Os três últimos ítens da Tabela III são referentes aos casos sobre os quais nada encontzamos ou sobre os quais as informações obtidas são insuficientes. 
Quanto ao setor militar, em termos de escolaridade, o potencial do PRF pode ser considerado baixo, principalmente se o compararmos com a frequência dos bacharéis. A atuação dos militares tinha se acentuado nas últimas décadas do século XIX, o que pode esclarecer a sua atuação na República. Então, como explicar o baixo índice de representatividade do militar nas fileiras do PRF? Isto talvez possa ser explicado se levarmos em conta a própria formação do PRF que nasceu para apoiar uma candidatura civil, embora, conforme já salientamos, alguns integrantes da agremiação relutassem em afirmar ser este um dos objetivos principais do partido. A participação ativa de elementos civis de grande destaque e a indiferença do próprio presidente em exercício, com o problema sucessório e a sua quase despreocupação com o Partido político que se formava contribuiram grandemente para essa predominância absoluta do poder civil (19). Some-se a isso ainda a indisposição entre Floriano e Prudente, o que naturalmente contribuiu e muito para a não estimulação, por parte dos chefes militares, da atuação de homens do exército nos quadros do novo órgão que atuaria na vida nacional: o PRF. Era um partido inspirado por civis e neles deveria se apoiar para o seu sucesso ou insucesso.

A formação acadêmica de um político pode e fornece dados relevantes ao entendimento de sua ação dentro dos quadros políticos em que sua atividade se desenrola.

Em termos da análise da vida, da personalidade e da ação de um dado personagem, a preocupação com a formação acadêmica e com as influências e informações recebidas durante essa época, deve' ser uma sequência das mais exploradas. Após o aprofundamento desta análise, em relação pelo menos aos membros mais relevantes e/ou atuantes de um partido pode-se ter certa medida do potencial do mesmo quanto a sua possibilidade de atuação, de percepção dos problemas sociais, econômicos e políticos do país, bem como das áreas em que, possivelmente seus membros poderiam ir em busca de apôio e mesmo de assessoramento em função das relações sociais e de amizade estabelecidas ainda nos bancos escolares. Isto é o óbvio. Constantemente se vê a composição de ministérios e secretariados de Estado, ainda hoje, formados, em grande parte, pelo companheirismo desenvolvido durante os períodos diferentes da vida escolar, ou pela relação de amizade originada nos ambientes de trabalho. E claro que não excluimos as composições que se fazem pelas pressões de vária natureza e que seria, tratada aqui, numa digressão total.

(19). - Outras eram as preocupações de Floriano: a política econômico-financeira e a pacificação dos movimentos armados. 
Mas acreditamos que a Tabela III tenha condições de demonstrar, de forma global, é verdade, a potencialidade do PRF. Permite tambem inferir a acentuada participação dos bachareis, não só pelo número significativo de elementos oriundos das faculdades de direito existentes no seio da agremiação, mas tambem pelo fato de serem eles os homens de maior importância e de grande influência na vida política e administrativa do país.

Alem do conhecimento do tipo de formação acadêmica dos políticos do PRF, achamos tambem de conveniência tentar elaborar uma tabela que nos mostrasse o vínculo profissional ao qual se ligavam os homens do partido de Glicério. Organizamos, então, a Tabela IV, que nos dá um quadro geral do que foram, em termos profissionais, os homens do PRF. Temos, então, a predominância, mais uma vez acentuada, dos bachareis $(17,30 \%)$, que exerciam a advocacia. Em seguida, tínhamos os médicos $(13,46 \%)$ e depois os militares $(10,57 \%)$. Os cargos da magistratura vinham logo após, em seguida os jornalistas.

Convem ressaltar a importância dos cargos da magistratura, se levarmos em conta a atuação de um juiz ou promotor em cidades do interior.

E sempre de se esperar que homens com formação universitária. como nos demonstra a Tabela IV, tenham uma visão mais ampla dos problemas políticos da nação.

A Tabela IV nos dá maiores esclarecimentos quanto à diversidade de profissionais que se agruparam para elaborar as bases da nova organização .

Tabela IV. - Profissões exercidas pelos signatários da Ata de Fundação do Partido, ao longo de suas vidas.

PROFISSÃO

Promotor Público

Juiz

Delegado

Procurador

Eclesiástico

Jornalista

Professor Universitário

Professor Escola Militar

Militar

Comerciante

Funcionário Público
FREQUENCIA

\section{8}

3

3

2

1

7

4

1

11

5

5
PORCENTAGEM *

$7,88 \%$

$2,88 \%$

$2,88 \%$

$1,92 \%$

$0,96 \%$

$6,74 \%$

$3,84 \%$

$0,96 \%$

$10,57 \%$

$4,80 \%$

$4,80 \%$ 


$\begin{array}{lrr}\text { Fazendeiro } & 3 & 2,88 \% \\ \text { Diplomata } & 1 & 0,96 \% \\ \text { Advogado } & 18 & 17,30 \% \\ \text { Engenheiro } & 3 & 2,88 \% \\ \text { Diretor de Escola } & 2 & 1,92 \% \\ \text { Professor }(* *) & 1 & 0,96 \% \\ \text { Médico } & 14 & 13,46 \% \\ \text { Desconhecidos } & 3 & 2,88 \% \\ \text { Assinatura Ilegivel } & 9 & 8,64 \% \\ \text { Total } & 104 & 100 \%\end{array}$

Alem dos bachareis, médicos e militares, que ocuparam uma posição destacada dentro do partido, tambem se destacaram os cargos da magistratura (promotor público, juiz, procurador). Conforme já salientamos, embora tenha uma representação quantitativamente inferior a outros profissionais representados, no PRF os cargos de promotoria, juizado e procuradoria eram altamente valorizados em suas localidades o que lhes conferia um voto de qualidade bastante significativo. Alem destes, cujas opiniões indiscutivelmente pesavam na opinião pública das cidades e municípios, onde exerciam suas funções, pode-se lembrar o prestígio dos delegados de polícia, no interior.

Entretanto, quantitativamente, excluidos os últimos dois itens da Tabela IV (20) temos a seguinte ordem de profissionais: promotores públicos, jornalistas, comerciantes, funcionários públicos, professores universitários, e em menor escala: engenheiros, clérigos, diplomatas, etc. .

Quantitativamente, era essa a situação do $\mathrm{PRF}$, em relação às categorias profissionais.

$\mathrm{O}$ aparecimento de um número significativo de comerciantes na organização do Partido Republicano Federal atesta a presença dos meios urbanos não intelectualizados na vida política nacional, o que demonstra a sua importância, não só neste momento, mas no último quartel do século XIX.

Chamamos a atenção para o aparecimento, no partido, de somente quatro fazendeiros. Estes seriam explicitamente os homens do mundo

$\left.{ }^{*}\right)$. - Porcentagem calculada sobre o total de assinaturas e não sobre o total de profissões exercidas, pois muitos signatários se ocuparam com mais de uma atividade.

(**). - Professor - Professor na Escola de Belas Artes.

(20). - "Desconhecidos (2,88\%).

Assinaturas Ilegiveis $(8,64 \%)$." 
rural a participar da agremiação. E claro que não estamos esquecidos de que, muitas das atuações político-partidárias desenvolvidas por bachareis em direito, médicos, etc., advogavam causas de interesses rurais $(21)$.

Simplesmente gostaríamos de chamar a atenção para o fato de que setenta e sete dos representantes do partido eram ligados a atividades eminentemente urbanas. Isto não quer dizer, é claro, que os integrantes do partido, no entanto, tratassem tão somente de assuntos ligados à urbanização, uma vez que, na maioria, eram os parlamentares e políticos ainda vinculados, por diferentes razões, ao meio rural.

Quando falamos de uma predominância do setor urbano sobre o setor rural dentro das hostes do PRF, estamos, evidentemente, tomando por base a classificação apresentada na Tabela III e com a especificidade ali apresentada. Não esquecemos, naturalmente, de que muitos dos representantes do PRF, embora qualificados como profissionais urbanos, poderiam defender interesses rurais. Não estamos, no entanto, no campo das inquirições a propósito da representatividade e da defesa de interesses deste ou daquele meio, mas simplesmente na constatação do predomínio de um sobre outro. Achamos, no entanto, que este dado nos lembra a importância que as cidades vão assumindo no final do século XIX no Brasil, evidenciando o fato da projeção que essas aglomerações urbanas vêm ganhando já a partir dos meados desse mesmo século.

Entretanto, apesar de lembrarmos esse desenvolvimento urbano e o princípio do seu predomínio sobre o mundo rural não podemos deixar de reconhecer que ainda neste momento de nossa História e até mesmo no século XX, as famílias tradicionais iriam exercer indiscutivelmente sua influência junto às agremiações políticas, principalmente nos agrupamentos locais (22).

(21). - Isto se prende ao fato de que muitos dos médicos, engenheiros, advogados estavam ligados por relações de parentesco aos senhores rurais.

(22). - Orlando Carvalho: "Como o p:oblema que nos interessa é o do exercício efetivo do poder político, vamos ver como se processava a sua localização".

"A tradição registrada por numerosos documentos valiosos é a de que, em Minas, a regra, até 1930, foi a existência nas comunidades locais de duas facções aglomeradas em torno de grandes famílias. No município, a luta era acirrada e, por vezes, violenta, marcada de episódios dramáticos, que acentuavam a divisão".

Luiz Silva, da Faculdade de Filosofia da Universidade de Minas Gerais, estudou a composição da liderança em Cachoeira do Campo e apurou que a chefia política local está, desde o Império, nas mãos de dois grupos de família.

Carlos Eloi de Carvalho Guimarães, da Faculdade de Direito da Universidade de Minas Gerais, estudou a evolução política de Dores do Indaia e 
Uma das questões menos controvertidas em termos da composição partidária do Partido Republicano Federal (PRF) tem sido a referente ao grande número de políticos do Partido Conservador (Império) que aderiu ao republicanismo. Porem, o fenômeno do adesismo político, no Brasil, não pode, nesse momento, ser circunscrito aos conservadores. As adesões vieram de todas as facções e partidos, de que se deu exemplo no início deste artigo. Faltam dados mais objetivos a respeito. No que tange ao PRF, as informações sobre este aspecto não são definitivas uma vez que dos personagens integrantes do partido, somente se obteve dados mais seguros em quarenta casos dos cento e quatro políticos que organizaram a agremiação.

Nesse levantamento efetuado pudemos constatar que os organizadores do PRF sairam das hostes não só do Partido Republicano (Histórico), mas dos partidos Liberal e Conservador, que após o movimento de novembro de 1889 aderiram ao regime republicano.

Alem dos republicanos ligados à propaganda e aos que aderiram ao republicanismo durante o Império por diferentes razões, conseguimos constatar que dentre os que compuseram o novo partido, em 1893, havia um maior número de conservadores do que de liberais (23).

Conforme se pode comprovar pelo cálculo percentual que efetuamos, os conservadores representavam $22 \%$ dos elementos fundadores do partido, enquanto os liberais atingiram uma porcentagem de $13 \%$. Isto nos dá idéia de quantos liberais e conservadores compuseram a instituição política que se instalou em julho de 1893 e alem disso comprova a expectativa de que maior fora o número de conservadores do que de liberais a aderir à causa republicana. No PRF, a regra foi confirmada. Dessa maneira, os políticos que formaram a agremiação eram de tendências bem diversas: liberais, conservadores e homens novos nas lides político-partidárias. Muitos deles talvez mesmo tenham passado a atuar do advento da República e até a partir do momento em que se propunha a formação do PRF.

verificou ter havido ali o predomínio de uma só família - a do Barão do Indaiá da data da criação do município, em 1880 até 1945 , quando o poder se dispersou Cf. Orlando de Carvalho, "Os Partidos Políticos em Minas Gerais, in II Seminário de Estudos Mineiros, realizado de 22 a 27 de outubro de 1956. Belo Horizonte, Minas Gerais.

(23). - Este cálculo foi feito tendo-se em conta as informações obtidas nas obras de referência por nós consultadas, especialmente Dunshee de Abranches, Governos e Congressos da República dos Estados Unidos do Brasil (1889-1917) . 2 volumes, São Paulo, 1918. Sob o item "em branco" catalogamos todos os elementos do partido sobre os quais as informações fossem incompletas ou pouco claras, alem daqueles aos quais somente havia referências depois do movimento de quinze de novembro de 1889 , ou ainda aqueles cujas assinaturas eram ilegiveis. 
Se as diversas categorias profissionais estavam representadas no Partido Republicano Federal, se liberais e conservadores se somaram aos republicanos, é verdade tambem que muitos daqueles que fundaram e lutaram pela implantação de uma agremiação partidária de âmbito nacional e com influência em todas as unidades da federação surgiram praticamente com os primórdios do Partido Republicano, em 1870 (24).

Não temos, por outro lado, dúvidas quanto ao papel importante e mesmo fundamental da atuação de Francisco Glicério. Não se pode negar, em momento algum, a condição de lider por ele exercida. Foi, a nosso ver, um político de extraordinárias qualidades individuais, capaz de aglutinar e coordenar as ações e somar pensamentos díspares ao mesmo tempo em que imprimia uma orientação às ações políticas nacionais. Já afirmamos não acreditar em "homens que mudam a História", mas não podemos deixar de reconhecer que dificilmente na História do Brasil se tem exemplo de dinamismo e capacidade de um homem na direção de uma agremiação partidária, tal como o demonstrou Glicério. Ao acentuarmos isto, não podemos deixar de ter em mente os homens que compuseram o PRF, para se ter a medida exata da capacidade de "aglutinador de homens"

"que Francisco Glicério demonstrou durante o período de tempo em que, como 'chefe' do partido, foi, de fato, o coordenador da vida política nacional".

No entanto, e apesar dessa liderança, o PRF era um partido com limitações, pela sua própria origem e motivação. Originário de um grupo regional, esteve sempre impregnado do cunho regionalista e paulista, não tendo atingido o seu objetivo de ser um organismo político-partidário nacional e, sendo sua principal meta a eleição do presidente da Repúb'ica, perdeu sua força tão logo passou a eleição. Com Prudente eleito, mantinha-se a força de Glicério e sua liderança, mas o partido se ressentia de um programa bem definido e da falta de uma ideologia para que sua sustentação não fosse feita pela tarefa isolada de seu lider. Essa falta de uma ideologia, de um programa, e o espírito antipartidário em termos nacionais levou o PRF a uma decomposição rápida. Era mesmo dificl manter coesa aquela "catedral aberta a todos os credos", pois nela se juntavam tanto liberais quanto conservadores históricos, republicanos históricos e de véspera e ainda os adesistas.

(24). - Francisco Glycério, Quintino Bocayuva, Rangel Pestana, Prudente de Moraes, Bernardino de Campos, etc. 
Embora prenhe mais de erros do que de acertos, embora de curta duração, o PRF teve, a nosso ver, um papel importante na evolução político-partidária da República Velha. Foi ele quem propiciou, durante a "gestação" da nossa história republicana, aos nossos homens públicos, condições para a realização da primeira experiência no campo da organização político-partidária, em âmbito nacional. Diante disso é que nos perguntamos se não foram as deficiências e as limitações do PRF, incapaz por si mesmo de transcender o regionalismo e a luta das facções locais, que inspiraram a "Política dos Governadores" de tão alto interesse e grande significado na história da política na República Velha.

JOSÉ SEbASTIÃo WITTER. - Nasceu em Fernando Prestes (SP), tendo cursado o ginásio e a escola Normal em Mogí das Cruzes e o curso superior na antiga Faculdade de Filosofia, Ciências e Letras da Universidade de São Paulo, onde se diplomou em 1961. Foi Professor primário (1954-1961) e Professor secundário (1961-1968). Em 1968, obteve o título de Mestre em História com a dissertação Um Estabelecimento Agrícola dos Meados do Século XIX em São Paulo, sobre a Fazenda Ibicaba, do Senador Vergueiro; em 1971, ainda pela mesma Faculdade, doutorou-se em História com a tese intitulada $\boldsymbol{A}$ Primeira Tentativa de Organização Partidária na República - o P.R. F. . Autor de inúmeros trabalhos, leciona no Departamento de História desde 1964, tendo-se especializado em História do Brasil. 